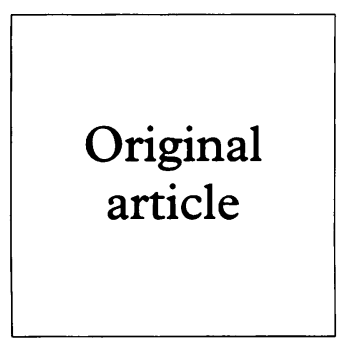

\title{
Characterisation of Neisseria gonorrhoeae in semen during urethral infection in men
}

\author{
Susan F Isbey, Timothy M Alcorn, Rachael H Davis, Julie Haizlip, Peter A Leone, \\ Myron S Cohen
}

Objective: To determine the number of Neisseria gonorrhoeae organisms in urine and semen in men with gonococcal urethritis, and to compare selected phenotypic characteristics of organisms harvested from the urethra and semen.

Design: Samples from two groups of subjects were examined. Patients with symptomatic urethritis receiving treatment at an STD clinic, as well as six subjects with experimental urethritis. Semen and urine specimens were obtained after the urethral exudate was sampled.

Results: Using quantitative cultures, we found an average of $6 \times 10^{6}$ gonococci in urine or semen of 17 men with symptomatic urethritis seeking treatment at an STD clinic, and $2 \times 10^{4}$ gonococci in secretions of six male subjects with early experimental infection. Gonococcal outer membrane opacity (Opa) proteins and lipo-oligosaccharide (LOS) recovered from urine and semen of these subjects were very similar.

Conclusions: Men with symptomatic gonorrhoea excrete a large number of gonococci in semen which is not affected by the duration of symptoms. The similar phenotype of organisms in urine and semen suggests the bacteria come from the same compartment. These data help to explain the efficiency of gonococcal transmission from men to their partners, and identify an appropriate target for a preventative vaccine or immunotherapy designed to reduce the inoculum in infected patients.

(Genitourin Med 1997;73:378-382)

Keywords: Neisseria gonorrhoeae; semen; gonorrhoea

\section{Introduction}

Neisseria gonorrhoeae is an obligate human mucosal pathogen that causes urethritis in the male and cervicitis in the female. ${ }^{1}$ Gonorrhoea is the most frequently reported bacterial infection in the United States, ${ }^{2}$ and more than 62 million cases of gonorrhoea occurred worldwide in 1995.3 About $10 \%$ to $20 \%$ of infected women with gonococcal cervicitis develop pelvic inflammatory disease (PID), ${ }^{45}$ which can lead to tubo-ovarian abscess, ectopic pregnancy, and sterility. ${ }^{1}$ There is also evidence that gonococcal infection facilitates transmission of the human immunodeficiency virus (HIV). ${ }^{67}$

A variety of factors affect the efficiency of transmission of STD pathogens, ${ }^{8}$ and these factors are probably quite different among males and females. $N$ gonorrhoeae is transmitted from females to their male partners approximately $20 \%$ of the time after a single episode of sexual intercourse, and $80 \%$ of the time after four episodes of intercourse. ${ }^{9}$ Male to female transmission of $N$ gonorrhoeae is more efficient; $50-90 \%$ of exposed women develop infection after a single episode of vaginal intercourse. ${ }^{10}$ The purulent urethral exudate characteristic of gonorrhoea is infectious, ${ }^{11}$ and it is likely that bacteria found in semen play a role in the transmission of disease from males to their sexual partners.

Successful infection with gonococci depends on the number of bacteria in the inoculum,,$^{12}$ and bacterial outer membrane components which allow attachment and invasion of epithelial cells (reviewed in Cohen and Sparling ${ }^{14}$ ). Specifically, outer membrane opacity (Opa) proteins and lipo-oligosaccharides side chains are believed to play a critical role in gonococcal attachment and invasion of mucosal epithelial cells. ${ }^{14}$ To address biological factors influencing the efficiency of transmission of $N$ gonorrhoeae we determined the number of gonococci in the urine and semen of men with natural and experimentally induced urethral infection. We also examined several outer membrane components believed to be important during gonococcal infection.

\section{Materials and methods}

Two cohorts were included in this study; patients seen at the Wake County STD Clinic in Raleigh, North Carolina ${ }^{15}$ and volunteer subjects enrolled in a study of experimental gonococcal urethritis conducted in the General Clinical Research Center at the University of North Carolina. ${ }^{12}$ Permission for the study of both cohort groups was obtained from the Committee on the Protection of the Rights of Human Subjects at the University of North Carolina at Chapel Hill. Patients visiting the STD clinic were eligible to participate in the study if they were 18 years of age or older, and presented to the clinic with symptomatic gonococcal urethritis. Inclusion in the study was based on presence of Gram negative intracellular diplococci on a Gram's stain of 
the urethral exudate. Patients with known HIV disease were excluded from participation. Subjects were asked to respond to a brief sexual history questionnaire, undergo urethral swab, and give full void urine and semen specimens for culture of gonococci. All responses to questions and experimental results were confidential. Participation in the experiment did not affect treatment of subjects, who were counselled by a physician care provider (PAL or SFI) and given ceftriaxone, ciprofloxacin or cefixime, and doxycycline. All subjects were reimbursed for their participation in the study.

We have developed an experimental model of human gonococcal urethritis to examine gonococcal virulence factors and as a paradigm for vaccine testing. ${ }^{12}$ Subjects participating in studies of experimental urethral gonorrhoea were recruited through advertisement, and admitted to the General Clinical Research Center. Procedures for the preparation of the gonococcal strain, urethral inoculation of subjects, and their observation during the course of the study have been described. ${ }^{12}$ Subjects were inoculated with gonococcal strain FA1090 variant A21. A piliated, Opa phenotype was selected. Subjects were inoculated through a No 8 French paediatric catheter moistened with sterile saline. ${ }^{12}$ All subjects were treated with ceftriaxone with the onset of a urethral discharge (and detection of organisms by Gram's stain as described above), or before release from the unit. Semen was collected from these subjects after collection of urine.

QUANTIFICATION OF GONOCOCCI IN URINE AND SEMEN

Full void, clean catch urine specimens were collected in sterile centrifuge bottles at the time of enrolment (WCHD subjects) or 21 and 45 hours after urethral inoculation (experimental urethritis subjects). Sample preparation, cultures, and enumeration of the gonococci in urine and semen were performed as previously described. ${ }^{15}$ Briefly, urine specimens were centrifuged at $1500 \times g$ for 10 minutes. The supernatants were decanted and the pellets containing the gonococci were resuspended in $600 \mu \mathrm{l}$ of gonococcal culture broth $(1.5 \% \mathrm{w} / \mathrm{v}$ proteose peptone, $86 \mathrm{mM}$ $\mathrm{NaCl}, 5.7 \mathrm{mM} \mathrm{KH} \mathrm{PO}_{4}, 29.9 \mathrm{mM} \mathrm{K} \mathrm{HPO}_{4}$ ), serially diluted from $10^{-1}$ to $10^{-6}$ and duplicate plated on selective commercially prepared media (Martin-Lewis media, BBL, Cockeysville, MD, USA). Vancomycin (VCN selective supplement, Unipath Ltd, Hampshire) was added to this selective media. To assure the recovery of vancomycin sensitive gonococci all specimens were also plated on chocolate media (BBL, Cokeysville, MD, USA). Plates were placed in candle extinction jars, transported to a 5\% carbon dioxide incubator at $37^{\circ} \mathrm{C}$, examined for growth, and counted at 24 and 48 hours.

In order to document our ability to recover gonococci from semen, specimens obtained by masturbation from healthy volunteers in the fertility clinic were "spiked" in the laboratory with gonococcal strain FA1090A21 (the strain used to infect experimental subjects as described above). Numbers of organisms recovered at various time points were determined. Two $1.5 \mathrm{ml}$ aliquots of a $\log$ phase broth culture of $N$ gonorrhoeae (each containing $1.8 \times 10^{7}$ colony forming units (CFU) were centrifuged at $12000 \times g$ for 30 seconds and the supernatants decanted. The pellets were resuspended in $100 \mu \mathrm{l}$ of GCB broth and inoculated into either $1.0 \mathrm{ml}$ of normal human semen or gonococcal culture broth (GCB) prepared as previously described. ${ }^{15}$ These suspensions were rotated at $12-15 \mathrm{rpm}$ in a $5 \%$ carbon dioxide incubator at $37^{\circ} \mathrm{C}$ and the number of CFU recovered from the suspension at 30 minutes and at 1,4 , and 20 hours after inoculation was determined. There was no significant difference in the numbers of gonococci recovered from semen compared with GCB for up to 4 hours of incubation. Significantly more bacteria were recovered from GCB compared with semen after 20 hours (data not shown).

Semen specimens from infected individuals were obtained immediately after urine specimens in sterile specimen cups. Fresh semen specimens were examined for viscosity and allowed to liquefy for up to 20 minutes at room temperature before dilution plating. In control experiments with split semen specimens from WCHD volunteers there were no significant differences between the numbers of viable organisms recovered from the semen plated immediately versus the liquefied sample obtained 20 minutes after collection (data not shown). Therefore, liquefied semen was used in all studies since it was easier to pipette accurately. For each volunteer, gonococci isolated from swab, urine, and semen samples were placed in trypticase soy broth medium containing $25 \%$ glycerol and frozen at $-70^{\circ} \mathrm{C}$.

\section{DETERMINATION OF OPACITY PROTEIN}

\section{EXPRESSION}

Monoclonal antibodies (mAbs) specific for Opa proteins of strain FA1090 1617 were used in colony and western blots to determine Opa expression of variants recovered from experimentally inoculated volunteers as previously described. ${ }^{1617}$ Suspensions of individual colonies from the primary isolation plates were spotted onto multiple nitrocellulose membranes (Schleicher and Schuell, Keene, NH, USA) and probed with Opa specific mAbs. The monoclonal antibodies used to differentiate Opa proteins expressed in strain FA1090 do not reliably differentiate Opa protein expression in wild type gonococcal strains. Therefore, Opa proteins from wild type gonococci were identified by heat modifiability in SDS-PAGE analysis using the Laemmli buffer system. ${ }^{1819}$ Gonococci isolated from frozen suspensions of urine and semen samples of WCHD subjects were streaked on selective media containing vancomycin, colistin, and nystatin (VCN plates) or onto chocolate media and grown overnight. Outer membranes were prepared by suspension of bacteria in $1 \mathrm{ml}$ lithium acetate buffer $(0.2 \mathrm{M}$ lithium chloride, $0 \cdot 1 \mathrm{M}$ sodium acetate, 

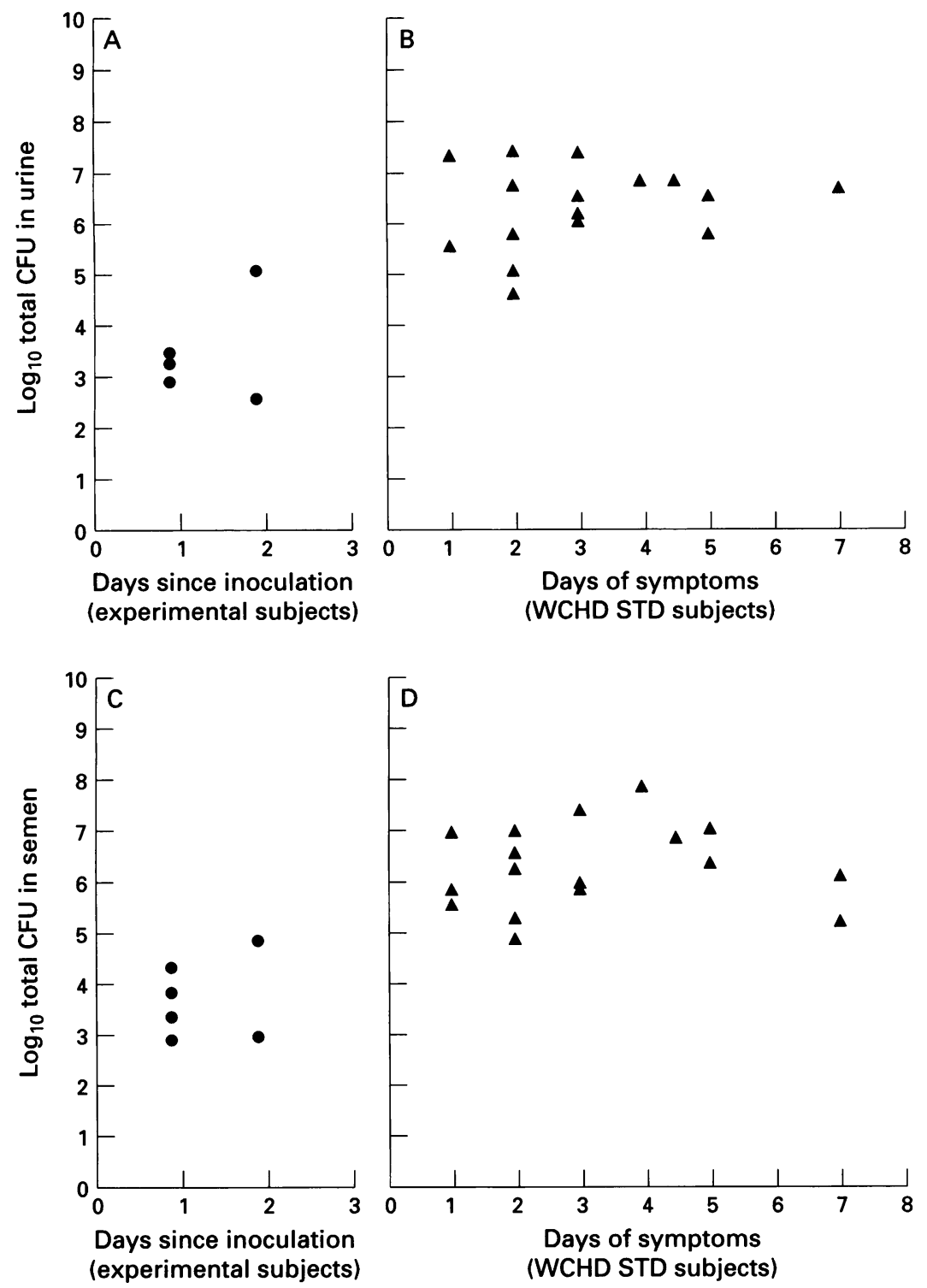

Figure 1 Correlation between the number of colony forming units (CFU) in urine or semen in six subjects with experimental urethritis or 17 STD clinic patients. Circles are used to describe urine $(A)$ and semen $(C)$ specimens in patients with experimental gonorrhoea, and triangles represent urine (B) and semen (D) specimens in STD clinic (WCHD STD) subjects; some symbols overlap. Nine patients providing urine samples were also included in an earlier study. ${ }^{15}$

$0.01 \mathrm{M}$ EDTA, pH 5.8) which was passed 15 times through a 22 gauge needle. Cellular debris was removed by centrifugation at 8000 $\times g$ for 15 minutes. ${ }^{19}$ The supernatant was then centrifuged at $100000 \times g$ for 2 hours at $4^{\circ} \mathrm{C}$. Pellets were resuspended in $100 \mu \mathrm{l}$ deionised water, vortexed for 1 minute, and centrifuged again at $14000 \times g$ for 1 minute. Twenty $\mu$ l aliquots of the supernatants were solubilised at $100^{\circ} \mathrm{C}$ for 10 minutes or $37^{\circ} \mathrm{C}$ for 1 hour and electrophoresed in $11 \%$ SDSpolyacrylamide gels with Laemmli buffers ${ }^{19}$ at $100 \mathrm{~V}$ for 2-3 hours. Gels were silver stained using the method of Tsai and Frasch. ${ }^{20}$

\section{DETERMINATION OF LIPO-OLIGOSACCHARIDE} (LOS) PHENOTYPE

LOS of gonococcal isolates was examined by a modification of the method of Hitchcock and Brown. ${ }^{21}$ Frozen primary isolates were subcultured onto GC agar plates and allowed to grow overnight at $37^{\circ} \mathrm{C}$ in an atmosphere con- taining $5 \%$ carbon dioxide. Colonies were scraped from the plate and suspended in Laemmli solubilisation buffer ${ }^{18}$ containing $4 \%$ SDS, $10 \%$ glycerol, $10 \% 2$-mercaptoethanol, and $0.125 \mathrm{M}$ Trizma base $(\mathrm{pH} 6.8)$ and heated to $100^{\circ} \mathrm{C}$ for 10 minutes. Twenty five $g$ of proteinase $\mathrm{K}$ (Gibco BRL, Gaithersburg, MD, USA) were added to the cell lysate and heated to $60^{\circ} \mathrm{C}$ for 1 hour. LOS of each sample were separated by SDS-PAGE using the Laemmli buffer system ${ }^{18}$ with a $21 \%$ resolving gel and a $4 \%$ stacking gel. Electrophoresis was carried out at $35 \mathrm{~mA}$ constant current. After soaking the gels in a solution of $10 \%$ acetic acid and $40 \%$ ethanol overnight, the LOS in the gels were oxidised by incubating the gels in a $1 \%$ solution of potassium dichromate for 30 minutes. LOS were then visualised by silver staining using the method of Tsai and Frasch. ${ }^{20}$ Individual LOS species of most gonococcal isolates were identified by SDSPAGE. Some isolates were further analysed by immunochemical analysis using monoclonal antibodies (mAbs) 3F11, 1-1-M, 4C4, and $4 \mathrm{C} 8$ provided by Campagnari et al. ${ }^{22}$

\section{Results}

We quantitated Neisseria gonorrhoeae in urine and semen specimens of subjects with symptomatic or experimental gonococcal urethritis. For 17 subjects with symptomatic gonococcal urethritis at the WCHD STD clinic, total gonococcal CFU in urine ranged from $3.7 \times$ $10^{4}$ to $2.6 \times 10^{7}$, with an average of $6.1 \times 10^{6}$ CFU (fig 1). Urine was collected before semen specimens for all but two subjects. The total CFU in semen ranged from $6.9 \times 10^{4}$ to 6.1 $\times 10^{7}$, with an average of $7.0 \times 10^{6} \mathrm{CFU}$. There was no correlation between the number of CFU present in urine or semen and sample volume or the duration of symptoms (data not shown) for an individual volunteer. However, there was a good correlation between the number of CFU in the semen and urine for each WCHD subject (linear correlation coefficient, $r=0.66$ ).

Six subjects inoculated participating in our studies of experimental gonococcal urethritis ${ }^{12}$ became infected within 45 hours. The average gonococcal CFU recovered from the urine for three volunteers treated at 21 hours (subjects 40,42 , and 43 ) was $1.8 \times 10^{3}$ per void (fig 1 ). The average number of CFU in semen specimens obtained from 21 to 45 hours after inoculation was $1.7 \times 10^{4}$ and was independent of the semen volume.

\section{SURFACE CHARACTERISTICS OF GONOCOCCI IN} URINE AND SEMEN

A large number of gonococci were recovered from semen even after swabbing of urethral exudate and full void urination. This observation led us to ask whether organisms recovered from urine and semen are similar or different in the expression of variable surface components such as LOS or Opa proteins. ${ }^{14}$ Opa proteins are antigenically variable, heat modifiable outer membrane proteins with apparent molecular mass of $30 \mathrm{kD} .{ }^{14161719}$ Opa proteins 
Figure 2 SDS-PAGE analysis of Opa protein expression of $N$

gonorrhoeae isolates from WCHD-STD volunteers 8 (lanes 1 and 2) and 5 (lanes 3 and 4) urine (U) and semen $(S)$ samples. The location of the porin protein (PI) is indicated on each gel as well as the approximate location of the Opa proteins. All proteins were solubilised at $100^{\circ} \mathrm{C}$ before electrophoresis. Gonococci isolated from volunteer 8 expressed $a$ single Opa protein lane

3), whereas urine isolates lane 4) expressed two different Opa proteins. Lane 5 contains protein molecular weight standards with the location of the $29 k D$ and $43 k D$ proteins marked.
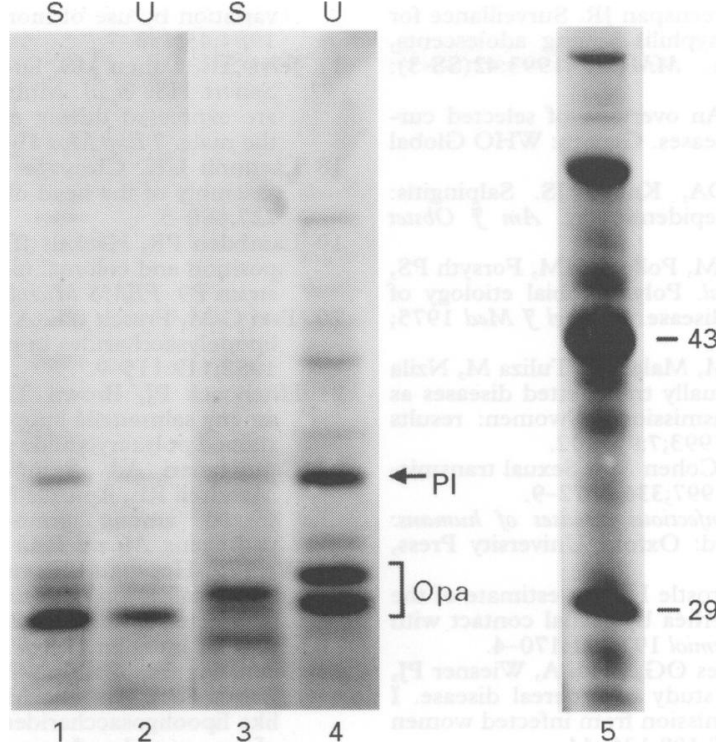

appear to play a role in the association of gonococci with epithelial cells. ${ }^{23}$

A panel of monoclonal antibodies (mAbs) reactive with the Opa proteins of strain FA1090 ${ }^{1617}$ enabled us to characterise the Opa proteins expressed by gonococci isolated from urine and semen specimens during experimental infection. Following experimental infection with an inoculum which was $89 \%$ Opa negative, the majority of isolates recovered from urine and semen of three subjects over 1 to 2 days expressed Opa proteins. For a given volunteer the repertoire of Opa proteins expressed by bacteria recovered from urine or semen was similar, and one or more of the major Opa proteins (expressed by $\geqslant 20 \%$ of the bacteria analysed) were the same (data not shown). FA1090 Opa protein mAbs are not specific for wild type gonococcal Opa proteins. Accordingly, Opa proteins from urine and semen samples of the WCHD isolates were compared by SDS-PAGE analysis. Opa proteins were identified by apparent molecular radius and heat modifiability. In six subjects the Opa proteins expressed in the urine and semen isolates were indistinguishable. In 1/7 subjects the Opa proteins expressed in the semen were different in size and number from those in urine (fig 2; lanes 3 and 4).

LOS is believed to evoke an inflammatory response and is a target for bactericidal antibodies. ${ }^{14}$ The LOS phenotype may affect the infectivity of the organism. ${ }^{1324}$ Examination of LOS from gonococci in urine and semen samples of eight WCHD clinic subjects and three experimental volunteers revealed no differences in apparent mobility of LOS by gel electrophoresis and/or antibody binding.

\section{Discussion}

The bacterial inoculum required to produce gonorrhoea in males or females is not known. In experimental models of male urethritis (reviewed in Cohen et $a^{12}$ ) the dose used to produce infection was $10^{2}$ to $10^{8} \mathrm{CFU}$, depending on the strain and variant used, and the experimental procedure employed..$^{12} 132425$ In all, $10^{2}$ to $10^{7}$ organisms have been recov- ered from cervical washings of female contacts of males with gonococcal urethritis. ${ }^{26}$ In the present study we examined numbers and some antigenic characteristics of gonococci in urine and semen. Symptomatic males with gonococcal urethritis have an average of $10^{6} \mathrm{CFU}$ in semen (obtained after swabbing the distal urethra and full void urination). This number was independent of either semen volume or duration of symptoms. It seems likely that the large concentration of gonococci in semen helps to explain the efficiency of transmission from men to their partners. ${ }^{10}$ In our experimental model of early human gonococcal urethritis, an average of $10^{4}$ organisms were present in urine and semen, most probably due to the short duration of infection in the experimental subjects. ${ }^{12}$

Outer membrane structures have been implicated as virulence factors. ${ }^{142324}$ Variation of LOS $^{24}$ and Opa proteins ${ }^{1727}$ recovered from different infected sites and at different times in the same patients have been described. In addition, in the current study gonococci were recovered from semen after urethral swabbing and urination, suggesting that gonococci in semen could reside in a separate compartment. However, Opa proteins and LOS expressed in urine and semen for each subject were nearly always the same, thereby suggesting a common mucosal source.

Gonococcal infections are common in both developed and developing countries. ${ }^{23}$ Gonorrhoea facilitates both the infectiousness and acquisition of HIV. ${ }^{78}$ Control of the spread of gonorrhoea is a critical global public health agenda. Such control can be realised in part by behavioural changes including reliable use of condoms, and by aggressive usage of single dose antibacterial therapy in patients, their partners, ${ }^{28}$ and in some cases whole communities. ${ }^{29}$ Nevertheless, development of a gonococcal vaccine remains critical. ${ }^{30} \mathrm{~A}$ gonococcal vaccine could be used to protect susceptible people at risk, and/or reduce the inoculum excreted in patients with gonococcal infection, so as to reduce the efficiency of transmission. Information regarding numbers of organisms excreted in the semen and the antigenic characteristics of organisms in vivo should prove helpful in these vaccine development efforts.

Results presented in part at the 33rd Interscience Conference on Antimicrobial Agents and Chemotherapy, 17 October 1993 New Orleans, LA (Abstract No 7).

Informed consent was obtained from all subjects enrolled in this study. The study was approved by the Committee on the this study. The study was approved by the Committee on the
Protection of the Rights of Human Subjects at the University of Protection of the Rights of Human Subjects at the University of North Carolina at Chapel Hill and the UNC Institutional Review Board. Human experimentation guidelines of the US Department of Health and Human

The conduct of the clinical research.
The conflict of interest related to this paper.

This work was supported by Public Health Service Gran U01 AI-331496 from the National Institute of Allergy and Infectious Diseases and the Verne S Caviness Clinical Research Center (No M01RR00046)

The authors would like to thank Penny M Drown, Larry $M$ Charniga, and Leesa Whicker for technical assistance, Dr Ann E Jerse for methodological advice, and Dr Janne G Cannon for Jerse for methodological advice, and Dr Janne G Cannon for of the manuscript.

1 Hook EW III, Handsfield HH. Gonococcal infections in the adult. In: Holmes KK, Mardh PA, Sparling PF, Wiesner PJ, eds. Sexually transmitted diseases. New York: McGraw-Hill, 1990:149-65. 
2 Webster LA, Berman SM, Greenspan JR. Surveillance for gonorrhea and secondary syphilis among adolescents, United States-1981-1991. MMWR 1993;42(SS-3): $1-11$.

3 World Health Organisation. An overview of selected curable sexually transmitted diseases. Geneva: WHO Global Programme on AIDS, 1995.

4 Holmes KK, Eschenbach DA, Knapp JS. Salpingitis: overview of etiology and epidemiology. Am $\mathscr{f}$ Obstet Gynecol 1980;138:893-900.

5 Eschenbach DA, Buchanan TM, Pollock HM, Forsyth PS, Alexander ER, Lin JS, et al. Polymicrobial etiology of acute pelvic inflammatory disease. $N$ Engl $\mathcal{F}$ Med 1975; 293:166-71.

6 Laga M, Manoka A, Kivuvu M, Malele B, Tuliza M, Nzila $\mathrm{N}$, et al. Non-ulcerative sexually transmitted diseases as risk factors for HIV-1 transmission in women: results from a cohort study. AIDS 1993;7:95-102.

7 Royce RA, Sena A, Cates W, Cohen MS. Sexual transmission of HIV. N Engl ₹ Med 1997;336:1072-9.

8 Anderson RM, May RM. Infectious diseases of humans: dynamics and control. Oxford: Oxford University Press, 1991.

9 Holmes KK, Johnson DW, Trostle HJ. An estimate of the risk of men acquiring gonorrhea by sexual contact with infected females. Am $\mathcal{F}$ Epidemiol 1970;91:170-4.

10 Hooper J, Reynolds GH, Jones OG, Zaidi A, Wiesner PJ Latimer KP, et al. Cohort study of venereal disease. The risk of gonorrhea transmission from infected women to men. Am $\mathcal{F}$ Epidemiol 1978;108:136-44.

11 Mahoney JF, Van Slyke CJ, Cutler JC, Blum HL. Experimental gonococcal urethritis in human volunteers. $A m \mathcal{F}$ Syph Gonorrhea Vener Dis 1946;30:1-39.

12 Cohen MS, Cannon JG, Jerse AE, Charniga LM, Isbey SF Whicker LG. Human experimentation with Neisseria gonorrhoeae: rationale, methods and implications for the biology of vaccine development. $\mathcal{F}$ Infect Dis 1994;169:532-7.

13 Schneider H, Cross AS, Kuschner RA, Taylor DN, Sadoff JC, Boslego JW, et al Experimental human gonococcal urethritis 250: Neisseria gonorrhoeae MS11 mkC are infective. F Infect Dis 1995;172:180-5

14 Cohen MS, Sparling PF. Mucosal infection with Neisseria gonorrhoeae: bacterial adaptation and mucosal defenses. $\mathcal{F}$ Clin Invest 1992;89:1699-705.

15 Haizlip J, Isbey SF, Hamilton HA, Jerse AE, Leone PA, Davis $\mathrm{RH}$, et al. Time required for elimination of Neisseria gonorrhoeae from the urogenital tract in men with symptomatic urethritis: comparison of oral and intramuscular single-dose therapy. Sex Transm Dis 1995; 22:145-8.

16 Black WJ, Schwalbe RS, Nachimkin I, Cannon JG. Characterization of Neisseria gonorrhoeae protein II phase variation by use of monoclonal antibodies. Infect Immun 1984;45:453-7.

17 Jerse AE, Cohen MS, Drown PM, Whicker LG, Isbey SF Seifert HS, et al. Multiple gonococcal opacity proteins are expressed during experimental urethral infection in the male. $\mathcal{E}$ Exp Med 1994;179:911-20.

$18 \mathrm{Laemmli}$ UK. Cleavage of structural proteins during the assembly of the head of bacteriophage T4. Nature 1970 227:680-5.

19 Lambden PR, Heckels JE. Outer membrane protein composition and colonial morphology of Neisseria gonorrhoea strain P9. FEMS Microbiol Lett 1979;5:263-5.

20 Tsai C-M, Frasch CE. A sensitive silver stain for detectin lipopolysaccharides in polyacrylamide gels. Anal Biochem 1982;119:115-9.

21 Hitchcock PJ, Brown TM. Morphological heterogeneity among salmonella lipopolysaccharide chemotype in silve stained polyacrylamide gels. $\mathcal{F}$ Bacteriol $1983 ; 154: 269-77$.

22 Campagnari AA, Spinola SM, Lesse AJ, Kwaik YA Mandrell RE, Apicella MA. Lipooligosaccharide epitopes Mandrell RE, Apicella MA. Lipooligosaccharide epitopes shared among gram-negative non-

23 Weel JF, Hopman CT, van Putten JPM. In situ expression and localization of Neisseria gonorrhoeae opacity protein in infected epithelial cells: apparent role of Opa proteins in cellular invasion. $\mathcal{F}$ Exp Med 1991;173:1395

24 Schneider H, Griffiss JM, Boslego JW, Hitchcock PJ Zahos KM, Apicella MA. Expression of paraglobosidelike lipooligosaccharides may be a necessary componen of gonococcal pathogenesis in men. 7 Exp Med 1991;174: 1601-6.

25 Swanson JK, Robbins K, Barerra O, Corwin J, Boslego J Ciak $M$, et al. Gonococcal pilin variants in experimental Ciak $M$, et al Goco

26 Lowe TL, Kraus SJ. Quantitation of Neisseria gonorrhoea from women with gonorrhea. F Infect Dis 1976;133: from $621-6$

27 Schwalbe RS, Sparling PF, Cannon JG. Variation of Neisseria gonorrhoeae protein II among isolates from an outbreak caused by a single gonococcal strain. Infect Immun 1985;49:250-2.

28 Cohen MS, Dallabetta G, Laga M, Holmes KK. A new deal in HIV prevention: lessons from the global approach. Ann Intern Med 1994;120:340-1.

29 Grosskurth H, Mosha F, Todd J, Mwijarubi E, Klokke A Senkorro K, et al. Impact of improved sexually transmitted diseases on HIV infection in rural Tanzania: randomised controlled trials. Lancet 1995;346:530-6.

30 The Jordan Report, 1993. Accelerated development of vaccines. Bethesda, MD: Division of Microbiology and Infectious Diseases, National Institute of Allergy and Infectious Diseases, National Institute of Aller
Infectious Diseases, National Institutes of Health. 